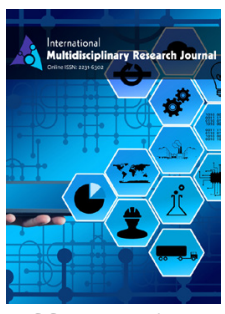

ISSN: $2231-6302$

Received: January 03, 2021 Revised: April 17, 2021 Accepted: April 22, 2021 Published: May 03, 2021

*Corresponding author: Md. Sajjat Hossain, E-mail: sajjathossainbrur@ gmail.com

\section{Coverage of Environmental Issues in Local Newspaper: an Analysis on Two Dailies of Rangpur, Bangladesh}

\author{
Md. Rahmatullah, Md. Tabiur Rahman Prodhan, Md. Nazrul Islam, Phd, \\ Md. Sajjat Hossain* \\ Department of Mass Communication and Journalism, Begum Rokeya University, Rangpur, Bangladesh
}

\begin{abstract}
This study examines the coverage of environmental issues in the local newspapers of Rangpur, Bangladesh. The results are based on an analysis of the content of environmental coverage in two local daily newspapers (The Daily Juger Alo and the Daily Prothom Khobor). The result depicts that The Daily Juger Alo and the Daily Prothom Khobor published an average of 1.91 and 1.22 stories per day, respectively. The top focused issue of these newspapers was natural disaster. Almost all the 258 (89.27\%) stories were published without deep investigations or in-depth analysis Researchers also found that the environmental issues coverage of these two newspapers was lack of diversification, lack of follow-up news and sufficient usage of illustration. However, based on the average daily coverage of environmental issues, the authors conclude that environmental journalism is a strong subfield in local newspapers of Rangpur, Bangladesh. Future studies need to consider a large number of samples.
\end{abstract}

KEYWORDS: Environmental issues, news coverage, local newspaper, Rangpur

\section{INTRODUCTION}

Today's world faces more and more environmental problems such as typhoons, cyclones, floods, landslides, hurricanes, earthquakes, deforestation, pollutions (water, air, and sound), global warming, droughts, etc. (Ferdous and Khatun, 2020). Some of these difficulties increased for human activities. Others are natural. People should have a good understanding of environmental concerns and problems in these circumstances because there is a strong connection between environment and development (Ferdous and Khatun, 2020). Bangladesh has experienced great economic development. Economic growth has resulted in higher incomes, better health indicators, and a decrease in overall poverty. Economic progress, on the other side, has adverse effects on the environment (Gallagher, 2009). Various environmental problems are arising during stages of development from basic needs to relative well-being in Bangladesh locally and nationally. As an ongoing developing country with a large population of 165 million(Worldometer, 2021), Bangladesh is facing serious environmental problems; most of the environmental issues are deforestation, climate change, environmental pollution, drought, increasing global warming, landslide, etc. these are the most influential factors that affect the development of the country, damage human health, life quality and ultimately the economy (Ferdous and Khatun, 2020).

Now a day's Environmental news and facts became a popular subject of conversation among the public and elites (Hasan and Pryanka, 2019). Therefore the mass media coverage concerning environmental news and information can play a pivotal role in increasing the awareness of people (Jharotia, 2018). In many perspectives, the most common and powerful means of mass communication is the print media and it plays a significant role in social change and education (Ferdous and Khatun, 2020). Several studies have shown that mass media is a powerful tool that has been and can continue to be used to effect social change. The mass media play a role as a channel and means for the environmental education of people in the world (Hoerisch, 2002). Among the mass media, the newspaper takes a significant place in disseminating information, shape perceptions, and create awareness and thus, catalyze environmental actions. Print media affects and forms readers' views by more in-depth reporting and analysis. This has the advantage of having a longer impact on the reader's minds, with more detailed reporting and investigation (Roba, 2012). News reports, in particular, play an important role in persuading the public and government to consider environmental concerns and problems to be resolved. (Truth about nursing, n.d.).

Copyright: (-) The authors. This article is open access and licensed under the terms of the Creative Commons Attribution License (http://creativecommons.org/licenses/by/4.0/) which permits unrestricted, use, distribution and reproduction in any medium, or format for any purpose, even commercially provided the work is properly cited. Attribution - You must give appropriate credit, provide a link to the license, and indicate if changes were made. 
Local and national newspapers of Bangladesh can play a crucial role in shaping and influencing public opinion regarding environmental issues by using news reports, writing editorial, and publishing experts' opinions. Features, photo features, post editorials, and expert articles on environmental issues such as flowers, medicinal plants, birds, and other species that have the threat of extinction are published by The Prothom Alo and The Daily Star (Islam, 2014). Environmental coverage of Bangladesh seeks to merge environmental and social concerns with economic and political perspectives. Relevant policies on national and global environmental problems have a major effect on public knowledge, environmental attitudes, and behavior. Bangladeshi mainstream media (newspapers) are also sufficiently strong to affect environmental policy and lift the voice of global climate change financing (Reza, 2010).

\section{Defining Keywords}

\section{Coverage}

The number of environmental stories that a newspaper published daily, the pattern of reporting, and treatment gave the stories that we call coverage in our research.

\section{Environmental issues}

In this research, we use environmental issues as pollution (air, sound, soil, etc.), climate change (CC), waste disposal (WD), deforestation, forestation, environment and health $(\mathrm{E} \& \mathrm{H})$, biodiversity, environment education and protection (EE \& P), fishery, global warming $(\mathrm{GW})$, natural disaster (ND), manmade disaster (MD) and few others issues."

\section{Local newspaper}

Researchers define locally published newspapers as local newspapers in this study. That means those newspapers are published from a specific region.

\section{RESEARCH PROBLEM}

Environmental issues and concerns are increasing gradually all over the world. Consequently, People should have a clear understanding of how these environmental issues and challenges arise, and what action needs to be taken. There is an increasing demand from the public for more and more information on environmental issues and great connection among understanding, knowledge, awareness, and taking action. In this context, socially responsible media in their coverage can make issues be seen as important at a given time in a given society by emphasizing such issues. It may be due to the frequency of reports, the attention given to the reports and investigate, follow up, and review of the concerned problems. Therefore, due to its major effect on human socio-economic life, this research study examines the print media coverage on environmental issues in local newspapers in Rangpur. Specifically, the existing research advances that the media give less attention to reporting environmental issues and problems. Considering these, the researchers will be searched to find the answer to the problem that 'Do local newspapers in Rangpur cover enough environmental issues?

\section{OBJECTIVES OF THE STUDY}

Each study has its own set of goals and objectives. Without targets and priorities, no work can be accomplished. The primary goal of this study is to learn more about how environmental issues are covered in local newspapers in Rangpur. However, there are two objectives that researchers try to obtain in this research.

1. To assess the coverage of environmental issues in Daily Juger Alo and Prothom Khobor.

2. To identify the reported environmental issues in Daily Juger Alo and Prothom Khobor.

\section{LITERATURE REVIEW}

Environmental organizations and the mass media are two main outlets for disseminating information about the environment to society. Via field staff, environmental agencies typically have some contact with scientists. They connect with the public through their channels: such as knowledge and education (I and $\mathrm{E}$ )offices. I and $\mathrm{E}$ offices also send messages such as news releases to the mass media while reporters still keep in touch with agency personnel to get the news (Witt, 1973).

In a study conducted by Jalarajan and Sreekumar (2011) where they showed that developing countries give more concern about poverty and underdevelopment than environmental issues. They also revealed that the idea of environmental journalism in Asian and third world countries is still new then developed countries.

The consistency of environmental news reporting has been criticized by several findings. Roba (2012) found that newspapers have not any permanent section where they can publish environmental issues. She also mentioned that media give much importance to other issues like agriculture, education, sport, health, and investment from environmental issues.

In another study by Hoerisch (2002), he found that the coverage of environmental concerns has improved in recent years, but there is still a comparatively low and one-sided range of environmental problems. He indicated that environmental issues would be strengthened. Das et al. (2009) concluded that Bangladesh's environmental reporting is a fast-growing sub-discipline of journalism that builds its own authenticity in ways that include social, political, and economic perspectives. In another study, Reza and Haque (2010) have portrayed a similar conclusion on environmental reporting in Bangladesh. Where they showed that the newspapers in Bangladesh gave special concentration to the effects and debates of global climate change these are especially pertinent to the environment of Bangladesh. They told that the newspapers set particular 
agenda on seminars and conferences, the effect of changes oppose changes, issues of indemnification, regional and local environmental issues. Both the dailies in Bangla and English language try to connect the regional issues with the global climate change.

\section{METHODS}

Quantitative and qualitative methods were used to achieve the study's objectives. The study of content materials yielded quantitative data. Tables and graphs were used to present quantitative data. To present the qualitative analysis researchers used narrative discussion. Neuendorf (2002) observes that the appropriate approach is to analyze the production of media Programs is content analysis. The goal of analyzing the media content is the accurate representation of a body or a message. The newspaper has a long history in Rangpur, Bangladesh. When the primary printing press become installation in East Bengal, it installation in Rangpur In 1847 to publish, 'Rangapur Bartabaha' turned into the earliest mission with inside the printing enterprise of the area (Banglapedia, 2015). Now there are some regional newspapers in Rangpur. Two newspapers have been decided on from them for the study. The titles of the newspapers that used for the study are the Daily Juger Alo (DJA) and the Daily Prothom Khobor (DPK). Researchers purposively selected these newspapers sample because these are significant for their readership, circulation, and also these are published daily. Researchers analyzed stories related to Environment in all issues of three continuous months from 1st June to 31 st August 2018, so the sample consists of a total of 184 newspapers.

\section{RESULT}

The data were analyzed according to the variables. This will help researchers to draw a conclusion that whether the media fail or succeed in coverage of the environment-related news.

\section{Descriptive Statistics of Environmental Issues Coverage}

During the time of content analysis researchers find out a total of 289 stories. Where the Daily Juger Alo had 176 articles concerning environmental issues and the Daily Prothom Khobor had 113 articles. The mean score of two local newspapers environmental issues coverage are $(\mathrm{M}=1.91, \mathrm{SD}=1.47)$ and $(\mathrm{M}=1.22, \mathrm{SD}=1.11)$. The DJA published the maximum 7 issues in a day, while the DPK published 5 stories (Table 1).

\section{Frequency of Story according to Month}

Table 2 shows that the highest stories were published in July. In July DJA and DPK published 95 (53.98\%) and 68 (60.18\%) stories respectively. It is because the world environment day was just behind and it became a major event for Bangladesh. The second highest stories were published in August. DJA published 43(24.43\%) and DPK published 25 (22.12\%) stories. In June DJA published 38 (21.59\%) stories and DPK published $20(17.70 \%)$ stories.

\section{Categories of Environmental Issues Covered by These} Two Newspapers

The following table has shown a significant difference in the number of categories of environmental issues printed by selected two newspapers and reporting trends throughout the three months of the study.

This study examined a total of 184 newspapers under the leading environmental issues. Leading issues under environment included pollution, CC, WD, deforestation, forestation, E \& H, biodiversity, EE \& P, fishery, GW, ND, MD, and others. All the classified issues in the DJA and the DPK totaled 176, and 113 , respectively. Among all the environmental issues in these two newspapers, the most $81(28.03 \%)$ were under natural disaster (ND) issues, while a little coverage was under E \& H $1(0.35 \%)$ and $\mathrm{EE} \mathrm{\&} \mathrm{P} 1$ (0.35\%). Pollution, CC, deforestation, E \& H, biodiversity, EE \& P, GW, ND, and MD issues published in the DJA were greater than the DPK. However, waste disposal, forestation, fishery, and other issues published in the DPK were more than the DJA (Table 3).

\section{Pattern of the Stories}

Table 4 revealed that these two newspapers published most of the stories have just reporting without in-depth reporting. The DJA and DPK respectively published 164 (93.18\%) and 94 $(83.19 \%)$ stories without any investigation or in-depth analysis of the environmental issues.

In the case of investigative news, DJA published only $6.82 \%$ stories whereas DPK published $16.81 \%$ stories. Follow up and law and policy related coverage were very low. More than half $74(65.49 \%)$ of the stories of the DPK use interpretation where less than one third $49(27.84 \%)$ of the stories use interpretation in DJA. Picture use rate was very low in DJA on the other side DPK uses picture in more than half of the stories related to environmental issues.

Table 1: Environmental issues coverage in two local newspapers in Rangpur

\begin{tabular}{llcc}
\hline Serial no & & Daily Juger Alo & Daily Prothom Khobor \\
\hline 1. & Mean & 1.91 & 1.22 \\
2. & Std. Error of Mean & 0.15 & 0.12 \\
3. & Median & 1.50 & 1 \\
4. & Std. Deviation & 1.47 & 1.11 \\
5. & Variance & 2.17 & 1.23 \\
6. & Skewness & 1.36 & 0.96 \\
7. & Kurtosis & 2.23 & 0.69 \\
8. & Minimum & 1 & 1 \\
9. & Maximum & 7 & 5 \\
10. & Total & 176 & 113 \\
\hline
\end{tabular}

Table 2: Frequency of story according to month

\begin{tabular}{llccc}
\hline Serial noNewspaper & June & July August & Total \\
\hline 1. & Daily Juger Alo & $38(21.59) 95(53.98) 43(24.43) 176(100)$ \\
& $N=176(\%)$ & & \\
2. & Daily Prothom & $20(17.70) 68(60.18) 25(22.12) 113(100)$ \\
& Kbobor $N=113(\%)$ &
\end{tabular}


Table 3: Categories of environmental issues covered by these two newspapers

\begin{tabular}{|c|c|c|c|c|}
\hline Serial no. & Environmental issues & Daily Juger Alo N (\%) & Daily Prothom Khobor N (\%) & Total N (\%) \\
\hline 1. & Pollution & 7 (3.98) & $1(0.89)$ & $8(2.77)$ \\
\hline 2. & Climate change (CC) & $3(1.70)$ & $1(0.89)$ & $4(1.38)$ \\
\hline 3. & Waste disposal (WD) & $3(1.70)$ & $4(3.54)$ & $7(2.42)$ \\
\hline 4. & Deforestation & $2(1.14)$ & $1(0.89)$ & $3(1.04)$ \\
\hline 5. & Forestation & $14(7.95)$ & $19(16.81)$ & $33(11.42)$ \\
\hline 6. & Environment and health ( $E$ \& H) & $1(0.57)$ & $0(0)$ & $1(0.35)$ \\
\hline 7. & Biodiversity & $2(1.14)$ & $0(0)$ & $2(0.69)$ \\
\hline 8. & Environment Education and protection (EE \&P) & $1(0.57)$ & $0(0)$ & $1(0.35)$ \\
\hline 9. & Fishery & $2(1.14)$ & $15(13.27)$ & $17(5.88)$ \\
\hline 10. & Global warming (GW) & $9(5.11)$ & $3(2.65)$ & $12(4.15)$ \\
\hline 11. & Natural disaster (ND) & $49(27.84)$ & $32(28.32)$ & $81(28.03)$ \\
\hline 12. & Manmade disaster (MD) & $60(34.09)$ & $13(11.50)$ & $73(25.26)$ \\
\hline 13. & Others & $23(13.07)$ & $24(21.24)$ & $47(16.26)$ \\
\hline
\end{tabular}

Table 4: Pattern of the news reporting in these newspapers

\begin{tabular}{llcccccc}
\hline Serial no & Newspaper & Just reporting & Investigative & Follow up & Jump news & Law and policy & Picture use \\
\hline 1. & Daily Juger Alo & $164(93.18 \%)$ & $12(6.82 \%)$ & $7(3.98 \%)$ & $49(27.84 \%)$ & $3(1.70 \%)$ & $21(11.93 \%)$ \\
2. & Daily Prothom Khobor & $94(83.19 \%)$ & $19(16.81 \%)$ & $4(3.54 \%)$ & $74(65.49 \%)$ & $5(4.42 \%)$ & $59(52.21 \%)$ \\
\hline
\end{tabular}

\section{Type of Story Published Related to Environmental Issues}

This study investigates the type of story published in these newspapers. Researchers were collected data used variables as a news report, editorial, and opinion. While news reports, editorial, and opinion gave 1, 2, and 3 points respectively. By analyzing the data following the table depict that these two newspapers give importance to news reporting. Where the mean score is of the DJA and the DPK are $(\mathrm{M}=1.17, \mathrm{SD}=0.55)$ and $(\mathrm{M}=1.04, \mathrm{SD}=0.21)$ respectively (Table 5$)$.

\section{Treatment of the News (Position of the Story)}

For measuring the treatment given to the environmental issues in two newspapers, researchers divide the newspaper pages into three categories. These are Frontpage, Back page, and others page, while front page, Back page, and other page are given 1, 2 , and 3 points, respectively. From the mean score of (Table 6), revealed that the DJA published most of the environmental issues in others and the Back page $(\mathrm{M}=2.48, \mathrm{SD}=0.73)$, while DPK published most of the stories in Back page, where the mean score is $(\mathrm{M}=1.74, \mathrm{SD}=0.55)$.

\section{Length of Stories of Juger Alo}

According to Figure 1, 107 (60.80\%) stories of Daily Juger Alo were positioned in 1-3 columns with 1-4 inches length. 47 $(26.70 \%)$ stories were positioned in $1-3$ columns with 4-8 inches length. 18 (10.23\%) stories were positioned in 1-3 columns with above 8 inches length. In 4-6 columns there were $3(1.70 \%)$ stories among them two stories had a length of 1-4 inches, one story had 4-8 inches. And in 7-8 columns there was only one $(0.57 \%)$ story which has a length of above 8 inches.

\section{Length of Stories of Prothom Khobor}

According to Figure 2, 55 (48.67\%) stories of Daily Prothom Khobor were positioned in 1-3 columns with 1-4 inches length.
Table 5: Type of story published related to environmental issues in two local newspapers

\begin{tabular}{llcc}
\hline Serial no & & Juger Alo & Prothom Khobor \\
\hline 1. & Mean & 1.17 & 1.04 \\
2. & Std. Error of Mean & 0.04 & 0.02 \\
3. & Median & 1 & 1 \\
4. & Std. Deviation & 0.55 & 0.21 \\
5. & Variance & 0.30 & 0.04 \\
6. & Skewness & 3.06 & 4.49 \\
7. & Kurtosis & 7.54 & 18.51 \\
8. & Minimum & 1 & 1 \\
9. & Maximum & 3 & 3 \\
\hline
\end{tabular}

Table 6: Treatment of environmental issues in two local newspapers

\begin{tabular}{llcc}
\hline Serial no & & Juger Alo & Prothom Khobor \\
\hline 1. & Mean & 2.48 & 1.74 \\
2. & Median & 3 & 2 \\
3. & Std. Deviation & 0.73 & 0.55 \\
4. & Variance & 0.53 & 0.30 \\
5. & Skewness & -1.01 & -0.07 \\
6. & Kurtosis & -0.38 & -0.36 \\
7. & Minimum & 1 & 1 \\
8. & Maximum & 3 & 3 \\
\hline
\end{tabular}

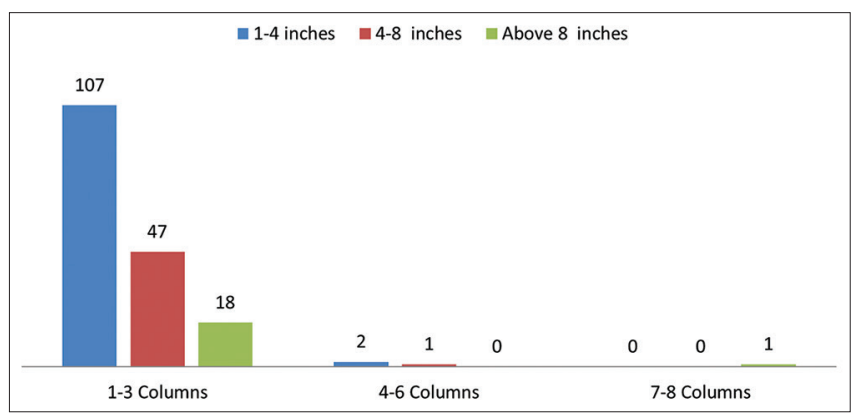

Figure 1: Length of the stories of Juger Alo

Int Multidiscip Res J • $2021 \quad \bullet \quad$ Vol 11 


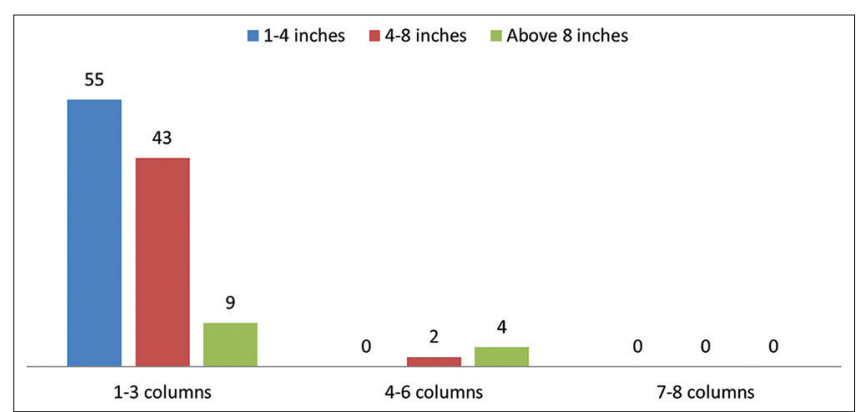

Figure 2: Length of stories of Prothom Khobor

$43(38.05 \%)$ stories were positioned in 1-3 columns with 4-8 inches length.

Nine $(7.96 \%)$ stories were positioned in 1-3 columns with above 8 inches length. In 4-6 columns there were $6(5.31 \%)$ stories among them two stories had 4-8 inches and four had more than 8 inches. And in 7-8 columns there was no story.

\section{Qualitative analysis of environmental issues}

In this portion, we discuss the coverage of the environmental issues using the qualitative approach of two local newspapers that was our study sample.

\section{Lack of diversification}

The local newspaper in Rangpur did not focus on internationally discussed environmental issues such as CC, increasing Venerable Energy Consumption (VEC), decrease fossil fuel (FF), GW, EE, health issues, WD, etc. On the other hand, they gave more priority to Disaster, forestation, etc. because of the local level approximation of the reader. But the researchers found out some lacking of diversification of global environmental issues in the local newspaper.

\section{Lack of in-depth reporting}

Maximum stories in the local newspaper regarding the environment were just reporting, which means when an event occurred newspaper report it. But they did not search for the reason behind it. During the research period, we discovered that there must be a dearth of in-depth reporting.

\section{Lack of follow-up}

During our study, we discovered just a small amount of follow-up news on environmental problems in two local newspapers. The bulk of the information hasn't been updated since it was first released. As a consequence, the reader is left in the dark about the results of any incident that happens related to the environment. Around the same time, the event remains unresolved due to non-disclosure of follow-up, and recurrence occurs.

\section{Sufficient usage of illustration}

Illustrations are very important for newspapers because it draws the reader's attention and generates more readership.
Sometimes it is better at communicating a story than the written word. However, in this study data analysis had found that these two local newspapers usage sufficient illustration with news stories related to environmental issues.

\section{DISCUSSION}

Bangladesh's most pressing concerns is the environment. This study investigates at how environmental issues are addressed in the local newspaper in Rangpur, Bangladesh. The present study finding depicts that 289 stories published in the DJA and the DPK during the three months of the study period. In a previous study by Hasan and Pryanka (2019) from May 15 to June 16, 2019, on two local dailies, where they found that 141 stories published in The Daily Purbokone and The Daily Azadi. Another study by Ferdous and Khatun (2020) showed that The Daily Star, The Daily Prothom Alo, The Daily New Age, and The Bangladesh Pratidin published 72 stories regarding the environment. From the analysis, researchers identified that the most $163(56.40 \%)$ environmental issues covered in the DJA and the DPK during July. Among all the environmental issues in these two newspapers, the most 81 (28.03\%) were under natural disaster (ND) issues. In a study conducted by Miah et al. (2011) revealed that the highest $(47 \%)$ of the issues were natural disaster-related. The majority of $258(89.27 \%)$ of the stories published by the DJA and the DPK were just reporting without any investigation or in-depth analysis. The previous study by Hasan and Pryanka (2019) found that most of their analyzed issues were just reporting. The current study researchers find out that the DJA and the DPK give importance to news reporting. These two newspapers published a little number of editorial and expert opinions. Frontpage is the most valuable and important page of the newspapers, where the important day's news covered by the newspapers followed by the Back page and then other pages. In this study, we found that the DJA published most of their environmental issues on the other page, while the DPK published in the Back page. Hasan and Pryanka (2019) study also mentions that the majority of the stories published on the inner page (others page). Most $107(60.80 \%)$ of the stories of Daily Juger Alo were positioned in 1-3 columns with 1-4 inches length and the Daily Prothom Khobor published 55 (48.67\%) stories in 1-3 columns with 1-4 inches length.

\section{CONCLUSION}

To come to an end that the local newspapers in Rangpur do cover environmental issues, and based on the average daily coverage of environmental issues, the authors conclude that environmental journalism is a strong subfield in local newspapers of Rangpur, Bangladesh, though some subject matter did not receive much coverage. It is decided that The Daily Juger Alo newspaper published the highest environmental articles giving more importance by contract to other newspapers. The result showed that the most emphasized environmental issues of the two newspapers are the same. It seemed that some important environmental issues like waste disposal, deforestation, climate change, and development related issues need to be more exposed and covered to educate the the public. 
Furthermore, all two newspapers have a comparatively small length of environmental coverage. Thus, the small length of coverage suggests more straightforward environmental news presented by the newspapers.

\section{LIMITATION OF THE STUDY}

The study is limited to Rangpur's two local newspapers; the daily Juger Alo and the daily Prothom Khobor, the reason being they are the most widely read papers and daily based published newspaper in Rangpur. Another limitation is unfortunately some of the environment-related content can be missing to analyze. The final limitation was three months is not enough to assess the newspaper coverage. So in the future, it is needed to analyze all over the year's content of the newspaper.

\section{SOURCE OF FINANCIAL SUPPORT}

There is no funding to be disclosed.

\section{CONFLICT OF INTEREST}

The authors declare that they have no competing interests.

\section{Abbreviations}

DJA- Daily Juger Alo, DPK -Daily Prothom Khobor, CCClimate change, WD- Waste disposal, E \& H- Environment and health, EE \& P- Environment Education and protection, FF-Fossil Fuel, GW- Global warming, ND- Natural disaster, MD- Manmade disaster, VEC-Venerable Energy Consumption

\section{REFERENCE}

Banglapedia (2015). Press, Retrieved from http://en.banglapedia.org/ index.php?title $=$ Press
Das, J., Bacon, W., \& Zaman, A. (2009). Covering the environmental issues and global warming in Delta land: A study of three newspapers. Pacific Journalism Review, 15(2), 10.

Ferdous, S., \& Khatun, M.(2020). News Coverage on Environmental Issues: A Study on Print Media of Bangladesh. IOSR Journal Of Humanities And Social Science, 25(4), 53-59.

Gallagher, K. P. (2009). Economic Globalization and the Environment, Annual Review of Environment and Resources, 34:, 279-304. https://doi. org/10.1146/annurev.environ.33.021407.092325

Hasan, S., \& Pryanka, D. (2019). Coverage of Environmental Issues in Local Dailies of Chattogram Centering World Environment Day. Socio Economic Challenges, 3(4), 63-71. https://doi.org/10.21272/ sec.3(4).63-71.2019

Hoerisch, H. (2002). A comparative study on environmental awareness and environmentally beneficial behavior in India. Report for CMS ENVIS Centre.

Islam, S. M. S. (2014). Print media coverage on climate change issues in Bangladesh. DIU Journal of Humanities and Social Science, 2, 113-128.

Jalarajan, R.S., Sreekumar, R. (2011). The commercial misrepresentation of environmental issues: comparing environmental media coverage in the first world and the developing nations. Amity Journal of Media and Communication Studies, 1(2), 1-11.

Jharotia, A. K. (2018). Role of Media in Enhancement of Environmental Awareness. Retrieved from https://www.researchgate.net/ publication/323751233 Role_of Media in_Enhancement_of Environmental_Awareness

Miah, M. D., Kabir, M. H., Koike, M., \& Akther, S. (2011). Major climatechange issues covered by the daily newspapers of Bangladesh. The Environmentalist, 31(1), 67-73. https://doi.org/10.1007/s10669-0109305-6

Neuendorf K. A. (2002). Defining content analysis. Content analysis guidebook. Thousand Oaks, CA: Sage.

Reza, S. S., \& Haque, A. (2010). From Development Communication to Development Journalism: Agenda Setting on Environmental Issues in Bangladesh News Media. In International Conference on Future Imperatives of Communication and Information for Development and Social Change (pp. 20-22).

Roba, T. F. (2012). Media and environmental awareness: a geographical study in Kembata Tembaro Zone, southern Ethiopia. (Doctoral dissertation).

Truth About Nursing. (n.d.). retrieved from https://www.truthaboutnursing. org/faq/media_affects_thinking.html\#gsc.tab $=0$

Witt, W. (1973). Communication concepts for science and environmental communications. The Journal of Environmental Education, 5(1), 58-62.

Worldometer (2021). Bangladesh population, retrieved from https://www. worldometers.info/world-population/bangladesh-population/ 